\title{
A Functional Hierarchy within the Parietofrontal Network in Stimulus Selection and Attention Control
}

\author{
Guilhem Ibos, Jean-René Duhamel, and Suliann Ben Hamed \\ Centre de Neuroscience Cognitive, CNRS UMR 5229, 69675 Bron cedex, Université Claude Bernard Lyon 1, France
}

\begin{abstract}
Although we are confronted with an ever-changing environment, we do not have the capacity to analyze all incoming sensory information. Perception is selective and is guided both by salient events occurring in our visual field and by cognitive premises about what needs our attention. Although the lateral intraparietal area (LIP) and frontal eye field (FEF) are known to represent the position of visual attention, their respective contributions to its control are still unclear. Here, we report LIP and FEF neuronal activities recorded while monkeys performed a voluntary attention-orientation target-detection task. We show that both encode behaviorally significant events, but that the FEF plays a specific role in mapping abstract cue instructions onto a spatial priority map to voluntarily guide attention. On the basis of a latency analysis, we show that the coding of stimulus identity and position precedes the emergence of an explicit attentional signal within the FEF. We also describe dynamic temporal hierarchies between LIP and FEF: stimuli carrying the highest intrinsic saliency are signaled by LIP before FEF, whereas stimuli carrying the highest extrinsic saliency are signaled in FEF before LIP. This suggests that whereas the parietofrontal attentional network most probably processes visual information in a recurrent way, exogenous processing predominates in the parietal cortex and the endogenous control of attention takes place in the FEF.
\end{abstract}

\section{Introduction}

In a complex visual environment, dedicated attention mechanisms set processing priorities among different object features or locations in space. The implication of the parietal cortex (Colby et al., 1996; Gottlieb et al., 1998; Corbetta and Shulman, 2002; Yantis et al., 2002; Herrington and Assad, 2009) and the prefrontal cortex (Moore and Armstrong, 2003; Moore and Fallah, 2004) in visuospatial attention is well established. However, orienting attention in space is not a unitary process. It can be bottom-up and stimulus-driven, induced by the intrinsic physical salience of visual stimuli, or it can be top-down, guided by stimulus relevance as defined by our internal goals or expectations. Neuronal correlates of both bottom-up and top-down attention have been identified in both the lateral intraparietal area (LIP) (Gottlieb et al., 1998; Bisley and Goldberg, 2003) and the frontal eye field (FEF) (Thompson and Bichot, 2005; Armstrong et al., 2009; Monosov and Thompson, 2009). Focal reversible inactivations of either cortical region (Wardak et al., 2004; Wardak et al., 2006) lead to significant behavioral impairments in easy visual search tasks that are known to rely on bottom-up attentional processes (Theeuwes, 1993) and in conjunction search tasks that are posited to mostly rely on top-down attentional processes, although

Received Aug. 24, 2012; revised March 11, 2013; accepted April 4, 2013.

Author contributions:G.I.,J.-R.D., and S.B.H. designed research;G.I. performed research;G.I.,J.-R.D., and S.B.H. contributed unpublished reagents/analytic tools; G.I. and S.B.H. analyzed data; G.I., J.-R.D., and S.B.H. wrote the paper.

This work was supported by the Agence Nationale Recherche (Grant \#ANR-05-JOC-0230-01 to S.B.H.). G.I was funded by the French Ministère de la Recherche and by the Fondation pour la Recherche Médicale. We thank C. Wardak, S. Wirth, and N.Y. Masse for constructive feedback on this work and J.-L. Charieau and F. Hérant for technical support.

The authors declare no competing financial interests.

Correspondence should be addressed to Suliann Ben Hamed, Centre de Neuroscience Cognitive, CNRS UMR 5529, Université Claude Bernard Lyon I, 67 Bd Pinel, 69675 Bron Cedex, France. E-mail: benhamed@isc.cnrs.fr.

DOI:10.1523/JNEUROSCI.4058-12.2013

Copyright $\odot 2013$ the authors $\quad 0270-6474 / 13 / 338359-11 \$ 15.00 / 0$ there is evidence that bottom-up processes and feature attention mechanisms are also involved (Zénon et al., 2009a, 2009b). As a result, the distinctive contributions of LIP and FEF to the allocation of visual attention in space are not clear. Few studies have investigated this issue directly (Chafee and Goldman-Rakic, 2000; Buschman and Miller, 2007; Katsuki and Constantinidis, 2012). Buschman and Miller (2007) showed that, during a conjunction visual search task, prefrontal neurons signal target location before parietal neurons, whereas the temporal relation is reversed during an easy visual search task.

However, visual search tasks do not allow differentiation between spatial selection by attention (i.e., selecting a portion of space for enhanced processing) and stimulus selection (target detection), a process closely associated with visual awareness that is distinct from spatial attention but modulated by it (for review, see Lamme, 2004). Here, we present neuronal activities from LIP and the FEF and analyze two distinct neurophysiological signatures: (1) neuronal modulations reflecting spatial attention allocation (i.e., the selection of a portion of space for enhanced processing) after the interpretation of a visual cue and (2) neuronal modulations associated with the detection of a behaviorally significant endogenous target event. We provide evidence for functional and temporal differences within the parietofrontal network in their contribution to voluntary spatial attentional control and target detection.

\section{Materials and Methods}

All procedures were approved by the local animal care committee in compliance with the guidelines of the European Community on Animal Care.

Surgical procedure and FEF and LIP mapping. An MRI-compatible head restraint device and 2 recording chambers were positioned over the LIP and the FEF of one female (monkey M, $7 \mathrm{~kg}$ ) and one male (monkey 
$\mathrm{Z}, 10 \mathrm{~kg}$ ) monkey (Macaca mulata) using standard procedures (Wardak et al., 2004).

FEF sites were characterized as the sites of the anterior bank of the arcuate sulcus in which low-threshold microstimulations $(<50 \mu \mathrm{A})$ evoked systematic eye movements. The visuomotor response patterns on a classic memory-guided saccade task at these sites served as a confirmation (Bruce et al., 1985; Colby and Goldberg, 1999). LIP sites were characterized on the basis of their visuomotor responses in a memory-guided saccade task (Gnadt and Andersen, 1988). In both areas, we specifically selected the cortical positions at which evoked saccade amplitude and visual or motor receptive field (RF) position ranged between $10^{\circ}$ and $15^{\circ}$. Recordings on the main task started upon the identification of visual, saccadic, or delay responses in a memory-guided saccade task. As a result, our neuronal dataset can be considered heterogeneous (Premereur et al., 2011) and minimally biased toward a given functional type compared with other studies.

Behavioral procedures. Monkeys were seated with their heads restrained facing a translucent tangent screen placed $35 \mathrm{~cm}$ away from them. Stimuli were back-projected onto this screen by a Davis DL-450 video projector. Experimental control was achieved by a real-time data acquisition system (REX; Hays et al., 1982) interfaced with a visual presentation computer running a dedicated custom software (Sclavus). The timing performance of the video projector was tested using a photoelectric cell monitoring of stimuli projection and was adjusted for during data analysis. Eye position was acquired with a video eye tracking system (EyeScan) digitized at $250 \mathrm{~Hz}$.

Cued dual stream rapid serial visual presentation task. We trained 2 monkeys to perform a cued version of a dual peripheral stream Rapid Serial Visual Presentation (RSVP) task. They had to detect the appearance of a target image in one of two streams and report it as quickly as possible by releasing a bar. A cue image embedded in the first stream predicted with a given probability whether the target would subsequently appear in the first stimulus stream or in the other stimulus stream.

Each trial began when the monkeys held the bar and fixated a central spot within a virtual square of $2.5^{\circ}$ wide. Any fixation break or bar release immediately interrupted the ongoing trial. Five hundred milliseconds after fixation onset, a rapid succession of 150-ms-long visual items, with no intervening blanks, began at one of two possible locations on the screen (Fig. 1-1). This stream of stimuli will be called the "first stream." Three-hundred milliseconds (i.e., two stimuli) later, a "second stream" appeared at the second location. From this point on, stimuli on both streams were presented synchronously. Three hundred to $600 \mathrm{~ms}$ (i.e., two to four stimuli) after the onset of the second stream, a cue image appeared in the first stream. A target was then presented and the monkey had to detect it as fast as possible for a liquid reward. In target trials $(80 \%$ of all trials), the cue indicated where the target would appear with a probability of $80 \%$ (i.e., probability of $64 \%$ over all trials). We refer to the cue indicating that the target will appear in the second stream as the "Shift" cue and the cue indicating that the target will appear in the first stream as the "Stay" cue. Targets that match cue instruction are called "valid target" (and "invalid target" otherwise). The target could appear at different time intervals from the cue (cue to target onset asynchronies, CTOAs: $150,300,600$, and $900 \mathrm{~ms}$ ). The monkeys had to report target's presence by releasing the bar for a liquid reward. Bar releases shorter than $150 \mathrm{~ms}$ from target presentation were counted as anticipations. Bar releases longer than $750 \mathrm{~ms}$ were discarded as false alarms (FAs). Twenty percent of the trials were catch trials in which no target was present and monkeys were rewarded for holding the bar up to the end of the trial. First stream position, cue type, target validity, and CTOA were pseudorandomly distributed throughout the experimental session. The two streams of stimuli were placed symmetrically from the fixation point so that one of them was always placed in the RF of the cell being recorded from.

Visual stimuli. Visual stimuli $\left(32 \times 32\right.$ pixels, $2^{\circ} \times 2^{\circ}$ of visual angle $)$ consisted of two gray values patterns (RGB gray [0.47 0.47 0.47] and RGB gray $[0.530 .530 .53])$. All stimuli were isoluminent equal mean gray level stimuli containing between two and six horizontal and vertical spatial cycles, except for the target which was composed of just one horizontal and one vertical cycle. The cues had identical spatial frequencies differing only in that the Shift cue was slightly red (RGB [ 10.470 .47 ] and RGB gray $\left[\begin{array}{lll}0.53 & 0.53 & 0.53\end{array}\right]$ ) and the Stay cue was slightly green (RGB [ $\left.\begin{array}{llll}0.47 & 1 & 0.47\end{array}\right]$ and RGB gray [0.53 0.530 .53$]$ ).

Data acquisition and sorting. Recordings were performed using both single tungsten electrodes (Frederick Haer) and platinum/tungsten tetrodes (Thomas Recording). Electrodes were lowered with a NAN electrode microdrive (or two such microdrives in the case of joint LIP and FEF recordings). Electrophysiological signals were amplified and spikes were digitized at $20,000 \mathrm{~Hz}$ (Plexon) with National Instruments cards controlled by a custom data acquisition software. Single units were sorted offline using Offline Sorter software (Plexon).

Data analysis. To dissociate cue-related from target-related activities, the trials in which the target occurred right after cue presentation (i.e., $150 \mathrm{~ms}$ after cue onset, first CTOA) were discarded. The response of each cell to each event was estimated using multiple successive bin-wise ANOVAS on the number of spikes in two adjacent $100 \mathrm{~ms}$ time windows in steps of $1 \mathrm{~ms}$ ( $p<0.01$; Ben Hamed and Duhamel, 2002). A cell was considered as event related when the ANOVA reached and maintained significance for at least 30 of $35 \mathrm{~ms}$ in a time interval of between 30 and $300 \mathrm{~ms}$ after the event of interest. All analyses were performed on valid correct trials. Single cell responses are displayed using a spike density function with a Gaussian kernel and a $\sigma$ of $20 \mathrm{~ms}$. For population plots, neuronal activity was first normalized (with respect to each cell's maximum of discharge rate) and then averaged over all the selected subpopulation.

Target and cue-related cells are defined as those cells in which activity changed significantly with respect to the baseline in the 30-300 ms after target and cue presentation, respectively (sliding ANOVA procedure described above). Target-related cells responded to at least one of the two possible target configurations (inside or opposite the RF). Their response latency was defined as the point after target presentation at which the $p$-value crossed the significance value and remained significant for at least 30 of $35 \mathrm{~ms}$. Cue-related cells responded to at least one of the four possible cue configurations (Shift or Stay cue, inside or opposite the RF). Their response latency was defined using receiver operator characteristic (ROC) analysis (see below).

$R O C$ analyses. The task used in this study presents the complexity that the response to a cue can be addressed both to the presentation of a single cue and to the associated attention orientation instruction, so it is difficult to describe the complexity of the cell's responses only with ANOVAs. To address this issue, we performed four different ROC analyses (Green and Swets, 1966) on those cells previously defined as cue responsive. ROC is a nonparametric statistic that allows for a qualitative estimation of the degree of overlap of two distributions of firing rates regardless of any specific a priori about normality or homoscedasticity. Two perfectly overlapping distributions will yield a ROC value of 0.5 . Two completely different distributions will yield a ROC value of 1 or 0 depending on the directionality of the comparison.

Specifically, at each $1 \mathrm{~ms}$ time step, a ROC value was calculated by comparing the trial-by-trial spike counts of both conditions of interest in the $100 \mathrm{~ms}$ window centered on this time step. ROC values could vary above or below 0.5 . For the sake of clarity, when comparing the different ROC analyses across the neuronal population, these values were rectified so that the ROC values in time varied between 0.5 and 1 . ROC measures were rectified as follows: rectified ROC value $=0.5+\mid 0.5-$ ROC value $\mid$. This allowed us to identify those cells selectively discriminating between attention within the RF versus attention away from the RF or cue within the RF versus cue away from the RF, and whether this corresponded to an increased or a decreased neuronal response in the first condition with respect to the second condition. Overall, $\sim 75 \%$ of the cells had a preferential enhanced neuronal response for the contralateral side (attention or position) with respect to the ipsilateral side $(n=79 / 112,70 \%)$. The neuronal responses being compared were considered significantly different when the ROC value rose above a threshold of 2.5 times the SD of the ROC baseline (calculated over a time window of $100 \mathrm{~ms}$ preceding cue onset) for $25 \mathrm{~ms}$ in a time window of $30 \mathrm{~ms}$. We performed four different ROC analyses: (1) attentional ROC (Fig. 4B1), comparing neuronal responses of trials during which the cue instructed attention within the RF (Stay cue inside RF + Shift cue outside RF) with trials during which the 
cue instructed attention away from the RF (Stay cue outside RF + Shift cue inside RF); (2) positional ROC (Fig. 4B2), comparing neuronal responses of trials during which the cue was presented within the RF (Stay cue inside RF + Shift cue inside RF) with trials during which the cue was presented away from the RF (Stay cue outside RF + Shift cue outside RF); (3) Shift ROC (data not shown), comparing responses to a Shift cue inside the RF with an ipsilateral Shift cue outside the RF; and (4) Stay ROC (data not shown), comparing responses to a contralateral Stay cue with an ipsilateral Stay cue.

Latency of cue-related cells. Because a given cell can significantly respond to several independent cue configurations with different timings, we define, for each cell, a unique cue-related response latency as the point in time at which the first of these four previously described ROC signals reaches the significance threshold.

Cue-cells classification. We used a bootstrap analysis to classify neurons into three different categories and differentiate the attention and the position information carried by each. Specifically, and for each condition (ipsilateral Shift cue, contralateral Shift cue, ipsilateral Stay cue, and contralateral Stay cue), we sampled, with replacement, as many trials as available. For example, if for a given cell 10 contralateral Stay trials were available, we drew randomly a first trial from the 10 possible trials, placed it back in the trial pool, and drew a second trial from the same 10 possible trials. This second trial had a probability of $1 / 10$ of being identical to the first trial (sampling with replacement). This procedure was repeated until 10 trials were sampled for the contralateral Stay condition. The same procedure was repeated for the other cue conditions. We used these selected trials to compute an attention index in time (|attention contraattention ipsi/attention contra + attention ipsi|) and a position index in time (|position contra-position ipsi/position contra-position ipsi|). Each index in time was computed from neuronal activities averaged over a 100 $\mathrm{ms}$ time window in time steps of $1 \mathrm{~ms}$. We then calculated the difference between the attention and the position indices $\left(I_{\mathrm{AP}}\right)$. This entire sampling with replacement procedure was then repeated 10,000 times and an average $I_{\mathrm{AP}}$ index in time was obtained for each cell.

To estimate whether the difference between the attention index and the position index was statistically significant, we performed a permutation test as follows. For each cell, we randomly reassigned all the available trials to the four different cue categories according to their respective number of trials (ipsilateral Shift cue, contralateral Shift cue, ipsilateral Stay cue, and contralateral Stay cue) irrespective of the exact cue configuration to which they corresponded. We then calculated an $I_{\mathrm{AP}}$ index as described above. This $I_{\mathrm{AP}}$ index, derived from the permutation of the available data, will be called a $\mathrm{p}-I_{\mathrm{AP}}$ index. This permutation procedure was performed 10,000 times to generate a distribution of $10,000 \mathrm{p}-I_{\mathrm{AP}}$ indices against which the real $I_{\mathrm{AP}}$ index was tested. We classified this cell as an "attention neuron" if its $I_{\mathrm{AP}}$ fell within the upper $5 \%$ of the permutated $I_{\mathrm{AP}}$ distribution for 25 of $30 \mathrm{~ms}$ after the cell's cue-related response onset. We classified it as a "position neuron" if its $I_{\mathrm{AP}}$ fell within the lower $5 \%$ of the permutated $I_{\mathrm{AP}}$ distribution for 25 of $30 \mathrm{~ms}$ after the cell's cue-related response onset. The remaining cells were classified as "cueselective cells." The distribution of the cue-related cells in these three categories between FEF and LIP were compared using a $\chi^{2}$ test.

\section{Results}

\section{Behavioral analysis}

Figure 1-1 provides a thorough description of the cued targetdetection task that the monkeys had to perform that is based on a dual RSVP (Yantis et al., 2002; Ibos et al., 2009). Monkeys had to detect a low saliency target that was embedded in one of the two continuous visual streams presented on the screen. A cue indicated the most probable target position when interpreted correctly. An optimal target-detection behavior in this demanding task requires the voluntary allocation of spatial attention to one of the two streams based on the advanced information provided by the cue. Optimal behavior is thus expected to correlate with significantly slower detection reaction times (RTs) in trials in which the target appears in the unpredicted stream (invalid trials) compared with trials in which it appears in the predicted stream

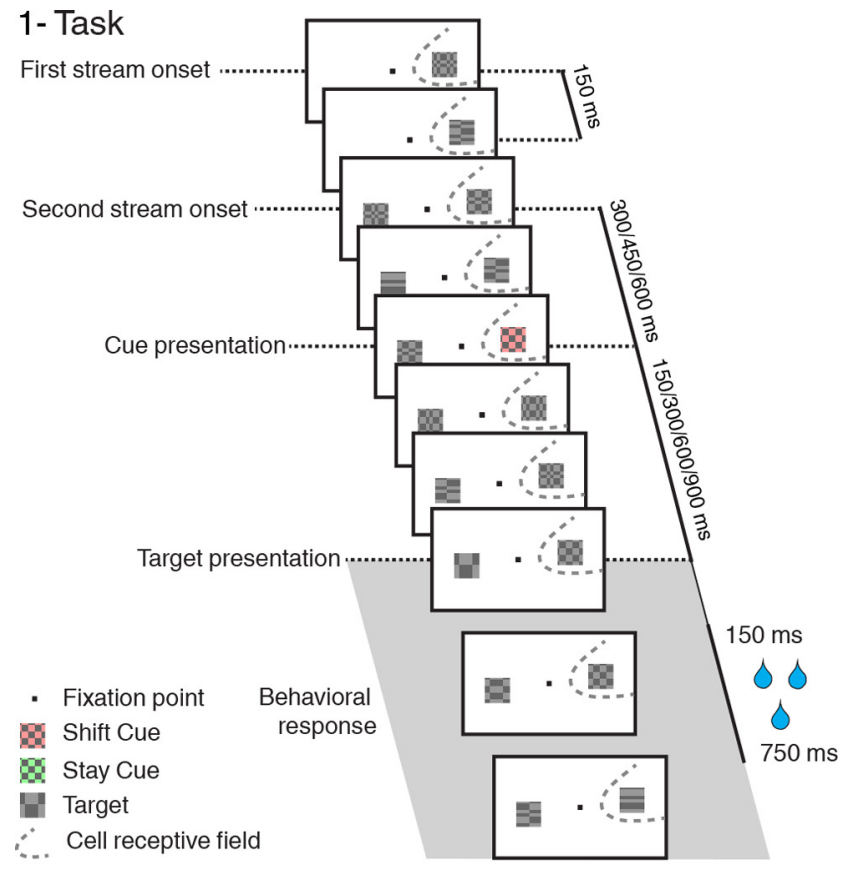

2- Reaction times
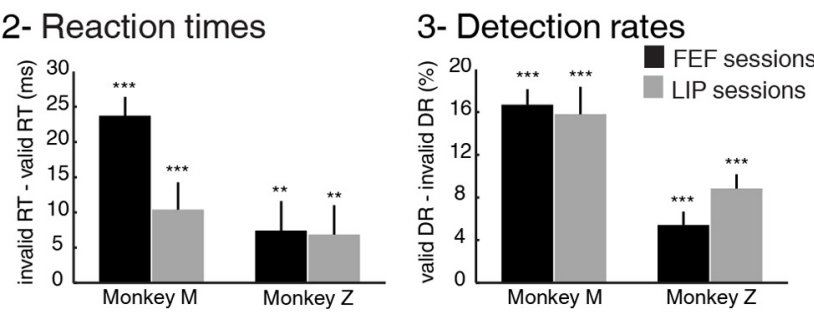

Figure 1. 1, Task description. The experimental procedure is a cued-target detection based on a dual RSVP paradigm (Yantis et al., 2002; Ibos et al., 2009). The monkey is required to maintain its gaze on the central fixation point all throughout the trial. A first stream of stimuli, a succession of visual stimuli every $150 \mathrm{~ms}$, is presented either within (as here) or opposite the fixation point from the cell's receptive field. Three hundred milliseconds later, a second stream appears opposite the first stream from the fixation point. Then, 300, 450, or $600 \mathrm{~ms}$ (here, 300 $\mathrm{ms}$ ) after the second stream onset, a cue is presented within the first stream. This cue can be a green Stay cue, indicating to the monkey that the target has an 64\% probability to appear within this very same stream, or a red Shift cue (as here), indicating that the target has a $64 \%$ probability to appear within the opposite stream. In $80 \%$ of the trials, the target is presented $150,300,600$, or 900 ms from cue onset. In $80 \%$ of these target trials (64\% of all trials), the target location is correctly predicted by the cue (valid target, as here). In $20 \%$ of these target trials ( $16 \%$ of all trials), the target location is incorrectly predicted by the cue (invalid target). In the remaining $20 \%$ of trials, no target is presented (catch trials) so as to discourage FAs. The target is composed of just one horizontal and one vertical spatial cycle, whereas distractor items are composed of up to six horizontal and vertical spatial cycles. The monkey gets rewarded for responding by a bar release between 150 and 750 ms after target presentation and for holding on to the bar when no target is presented. 2, 3, Cue validity effects. Both monkeys respond faster (2) and have higher DRs (3) on valid cue trials than on invalid cue trials (mean $\pm \mathrm{SE}$ ) in both the FEF (black) and LIP (gray) recording sessions. ${ }^{* *} p<0.01$; ${ }^{* * *} p<0.001$.

(valid trials). It is also expected to correlate with significantly higher detection rates (DRs) on valid trials than on invalid trials. As a result, only those sessions in which a validity effect could be seen on both RT and DR (91/95 sessions for monkey M and 32/35 sessions for monkey Z) are included in the present analysis. In these sessions, robust validity effects were measured for both monkeys in both RTs (Fig. 1-2, $t$ test, $p<0.001$ for monkey M and $p<0.01$ for monkey Z) and DRs (Fig. 1-3, $t$ test, $p<0.001$ for both monkeys). Table 1 provides additional details on the behavioral performance, including average RT, DR, and FA rates. These validity effects were present and not different ( $t$ test, $p>0.2$ ) in 
Table 1. Mean RTs, DRs, and FAs

\begin{tabular}{|c|c|c|c|c|c|c|c|c|}
\hline & \multicolumn{2}{|c|}{ Monkey M FEF } & \multicolumn{2}{|c|}{ Monkey M LIP } & \multicolumn{2}{|c|}{ Monkey Z FEF } & \multicolumn{2}{|c|}{ Monkey Z LIP } \\
\hline & Valid & Invalid & Valid & Invalid & Valid & Invalid & Valid & Invalid \\
\hline Mea & 457 & 480 & 474 & 484 & 414 & 422 & 413 & 420 \\
\hline Mean DR (\%) & 79.6 & 62.9 & 77 & 61.2 & 66.8 & 62.4 & 66 & 57.2 \\
\hline Mean FA (\%) & 22 & & 28 & & 39 & & 35 & \\
\hline
\end{tabular}

DRs are calculated as follows: hits/(hits + misses), where hits correspond to those target trials in which the monkey correctly produced a hand response from 150 to $750 \mathrm{~ms}$ after target presentation and misses correspond to all remaining target trials in which either an improper hand response was produced outside of the imposed response window or no hand response was given. FAs were calculated as follows: FAs/(FAs + correct rejections), where FAs correspond to those catch trials in which the monkey produced a hand response and correct rejections correspond to those in which the monkey correctly refrained from any hand response. Shown are FEF and LIP sessions and both valid and invalid trials (does not apply to FAs). Please note that DRs and FAs are not calculated over the same type of trials, so their sum does not amount to $100 \%$.

both sessions targeted to the parietal cortex (Fig. 1-2,3, gray) and those targeted to the prefrontal cortex (Fig. 1-2,3, black, 10 sessions with joint LIP and FEF recordings for monkey M and 6 for monkey Z). Variations in behavioral performance could thus not account for the functional differences between these two regions (described below).

In contrast to other tasks that require monitoring a single location and ignoring events taking place previously (Gregoriou et al., 2009), the task used in the present study involves the constant monitoring of two streams of stimuli. If this were not the case, the DRs of invalid targets would not be above chance (Table 1). As a result, the net effect of cue interpretation is best viewed as a reorientation of attention (i.e., a readjustment of the attentional biases toward each of the two streams), rather than as an all (Shift) or none (Stay) displacement of the attentional locus. In the following, Shift and Stay will be used to designate an attentional bias toward the second stream and the first stream, respectively.

\section{Neuronal recordings}

One of the two streams was systematically placed within the neuron's receptive field. Both areas responded with a short latency increase in firing rate at the onset of the stream that was aligned with the neuron's RF. A transient inhibition could also be seen when the second stream was presented away from the RF. These phasic responses to stream onset were followed by a lower tonic firing rate that was not modulated by the rhythm of image transitions, suggesting that whereas both areas did encode the presence of a visual stream into their receptive field, they did not encode the stream visual transients (Fig. 2). A total of 80 LIP and 123 FEF task-related neurons (i.e., neurons responding to flow, cue, or target onset) were recorded.

Our analyses focus on neuronal activity after cue and target onsets ( $n=99 / 123$ neurons in FEF and $n=63 / 80$ neurons in LIP). A substantial number of FEF and LIP neurons showed target-related activity only (FEF: $27 \%, n=27 / 99$ and LIP: $36 \%$, $n=23 / 63$ ). Figure $3-1$ shows an example of such a cell with no significant modulation after the cue, a clear response to a predicted and correctly detected contralateral target, but no response to a predicted and correctly detected ipsilateral target. Another important proportion of cells showed a combination of cue- and target-related activity (FEF: 59\%, $n=58 / 99$ and LIP: $46 \%, n=29 / 63$ ). Figure 3-2,3,4 shows three examples of such cue-target cells, with diverse modulations after the cue (analyzed below), a clear response to a predicted contralateral target, but no response to a predicted ipsilateral target. Only a small percentage of neurons responded to the cue only (FEF: 14\%, $n=14 / 99$ and LIP $17 \%, n=11 / 63)$. The specific neuronal activity patterns in response to cue and target events in each area are described next.

\section{FEF populationnal activity to Stream Onset}

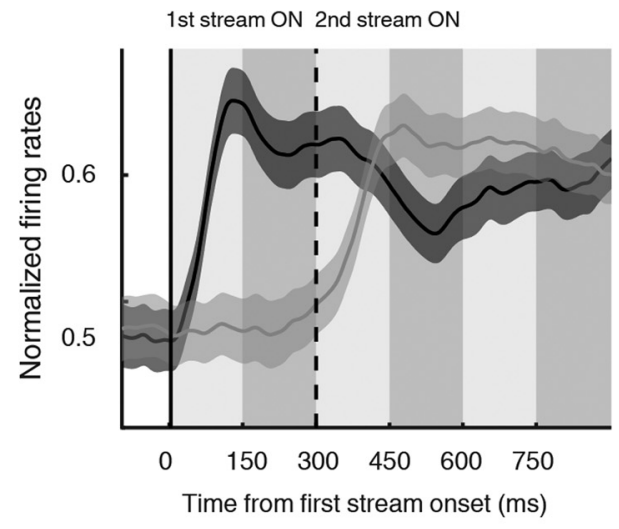

\section{LIP populationnal activity to Stream Onset}
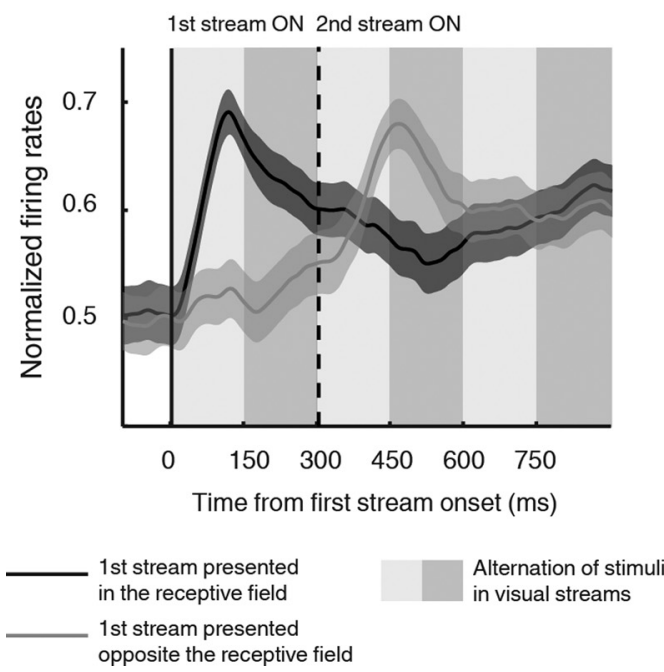

Figure 2. FEF and LIP population responses to the presentation of the visual streams. FEF (1) and LIP (2) population responses in trials in which the first stream was presented within the receptive field (black, mean $\pm \mathrm{SE}$ ) or opposite (gray), aligned on the first stream onset (continuous black vertical line) and simultaneously on the second stream onset (continuous dashed vertical line). The gray shades in the background correspond to the chronological succession of stimuli within each visual stream at a rate of one image per $150 \mathrm{~ms}$.

\section{Cue-related responses}

The cue image embedded in the first visual stream provides advanced information about target location. It should be stressed that to benefit from this cue, it is not sufficient to attend to the location where it appears - both its location and its identity need to be combined and interpreted. This is because, for example, a red cue on the right side means "target on the left" and a red cue on the left side means "target on the right." Therefore, in a first step, we identified the cue-related cells defined as those cells in which activity changed significantly with respect to the baseline in response to at least one of the four possible cue configurations (sliding ANOVA, $p<0.01$ ). Figure 3 illustrates the diversity of the observed cue-related responses (FEF: $n=72$, LIP: $n=40$ ). Some cells (selective cue cells), such as the LIP cell presented in Figure 3-2, selectively responded to a single type of cue (here, a Stay cue presented in the RF, blue response curve). A second group of cells (position cue cells), such as the FEF cell presented in Figure 3-3, responded when a cue was presented in the cell's RF whether it was a Shift or a Stay cue. Figure 3-4 shows a cell (at- 


\section{Target related cell, LIP}

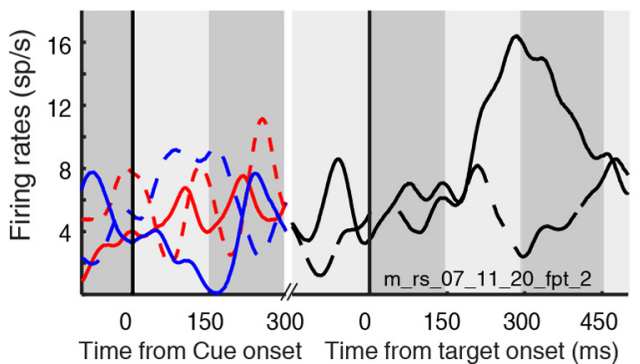

3. Position cell, Target responsive, FEF

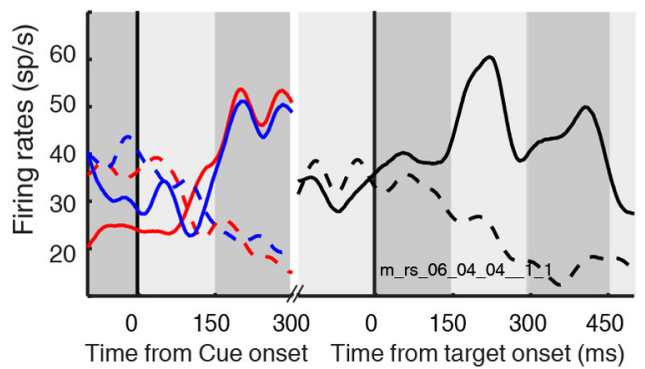

2. Cue-slective cell, Target responsive, LIP

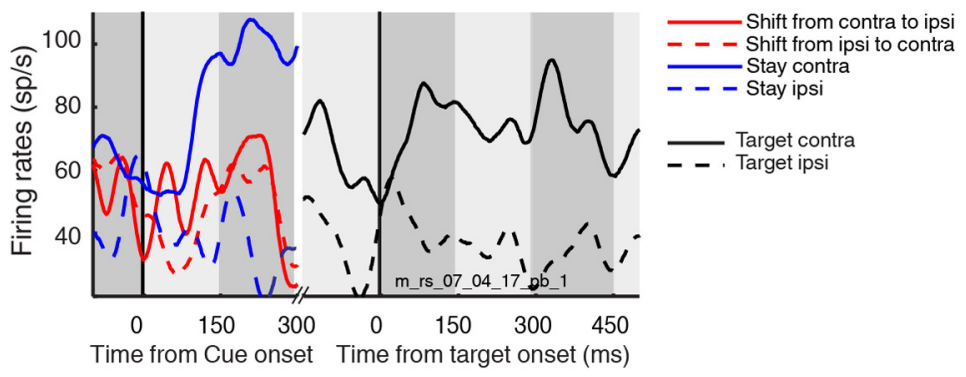

4. Attention cell, Target responsive, FEF

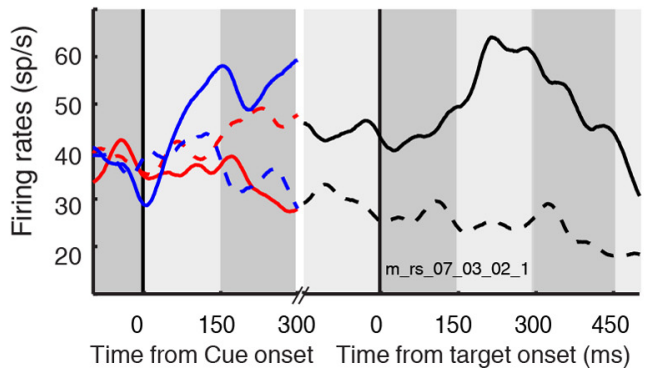

Figure 3. Cue and target-related activities: single cell examples. For each cell, spike-density functions are represented for each of the four possible cue configurations and each of the two target positions. Cue-related responses are estimated over all correct trials. Target-related responses are estimated over all validly cued correct trials. 1, Cell specifically responding to the target presented contralaterally to the recording site (inside its RF) and showing no selectivity to cues. 2, Cell specifically responding to a Stay cue and to a target presented contralaterally to the recording site (inside its RF). 3, Cell enhanced for contralateral cues and contralateral targets (inside its RF). 4, Cell enhanced when attention is instructed contralateral to the recording site for contralateral targets (inside its RF). Cue-related responses are color coded as follows: continuous blue corresponds to Stay contralateral trials, dashed blue corresponds to Stay ipsilateral trials, continuous red corresponds to Shift from contralateral to ipsilateral trials, dashed red corresponds to Shift from ipsilateral to contralateral trials, continuous black corresponds to contralateral target trials, dashed black corresponds to ipsilateral target trials. The gray shades in the background correspond to the chronological succession of stimuli within each visual stream at a rate of one image per $150 \mathrm{~ms}$.

tention cue cell) in which the response increased after a Stay cue presented contralaterally or a Shift cue presented ipsilaterally, both of which instructed attention toward its RF. Conversely, the spiking rate was diminished after either a Shift cue presented contralaterally or a Stay cue presented ipsilaterally (i.e., after a cue instructing attention away from its RF). To quantify the response patterns of each cue-related cell in both LIP and FEF, we measured its response selectivity in time to the position of attention instructed by the cue, using a normalized ROC analysis (Green and Swets, 1966). This procedure estimates the probability that an ideal observer can determine whether the subject's attention was allocated ipsilaterally or contralaterally based on the distribution of the firing rates associated with each condition (see "ROC analysis" section in Materials and Methods for a full description). A ROC index of 0.5 indicates no selectivity to attention allocation, whereas a ROC index $>0.5$ indicates a preferential coding for attention oriented in the RF with respect to the opposite field (see the "ROC analysis" section in Materials and Methods for details). Figure 4-1 represents the time course of this attentional ROC index around the cue (vertical red line) for each cell (along the $y$-axis, FEF cells, top, LIP cells, bottom). ROC indices are color coded such that an index of 0.5 is dark blue and higher-index values go from cyan to red.

We likewise measured the cells' response selectivity in time to cue position by estimating, using the same method, the probability that an ideal observer could determine whether the cue was presented ipsilaterally or contralaterally based on the distribution of firing rates associated with each condition. The corresponding position ROC indices are presented in Figure 4-2. To convey a better sense of what both attentional and positional ROC indices reflect in terms of spiking rates, small arrows along the $y$-axis of
Figure 4-1 indicate the ROC indices of the three exemplar cells presented in Figure 3. Although the attentional cell (blue arrow) reached the significance threshold only for attentional ROC indices and the positional cell (black arrow) reached significance only for positional ROC indices, the cue-selective cell actually remained below significance for both indices (red arrow) because this cell responds only to a contralateral Stay cue. As a result, it contributes to "attention contralateral," but insufficiently so because this signal is not reinforced by a significant response to an ipsilateral Shift cue. Likewise, this cell contributes to "cue contralateral," but, again, insufficiently so because this signal is not reinforced by a significant response to a contralateral Stay cue.

$I_{\mathrm{AP}}$, the average difference between the "instantaneous" attention and position indexes in time calculated using a bootstrap method and resampling trials with replacement (as described in the Materials and Methods), allowed us to better comprehend the relative contribution of each cell to attention or position coding (Fig. 4-3). The $I_{\mathrm{AP}}$ of the attentional cell (blue arrow) after cue onset was well above zero, whereas that of the position cell was below zero (black arrow). The $I_{\mathrm{AP}}$ of the cue-selective cell stayed around zero. To summarize these results across both FEF and LIP populations, we averaged the $I_{\mathrm{AP}}$ values from 0 to $50 \mathrm{~ms}$ after response onset (white ticks, see "Latency of cue-related cells" section in Materials and Methods for details). The cue-related $I_{\mathrm{AP}}$ distribution is represented in Figure 4-4 (top, FEF; bottom, LIP). The LIP $I_{\mathrm{AP}}$ distribution is significantly offset toward position coding (mean $=-0.03$, median $=-0.014$ ) with respect to the FEF $I_{\mathrm{AP}}$ distribution $($ mean $=0.03$, median $=0.018, t$ test, $p=0.03$ ). Cue cells were classified a posteriori into three functional categories based on the statistical difference between the instantaneous distribution of $I_{\mathrm{AP}}$ attentional and positional indexes in the $50 \mathrm{~ms}$ 
(1) ROC attention contra vs. ipsi

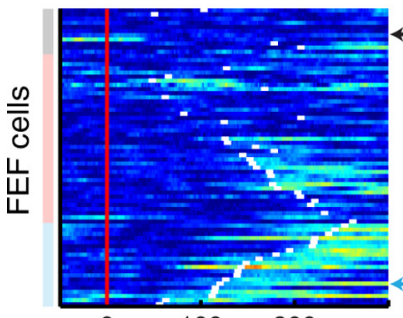

0

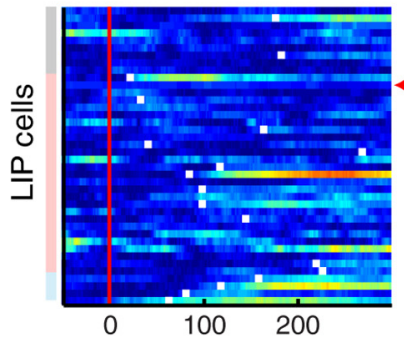

Time from cue onset (ms)
(2) ROC position contra vs. ipsi

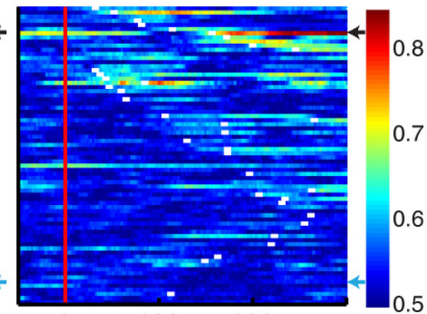

0

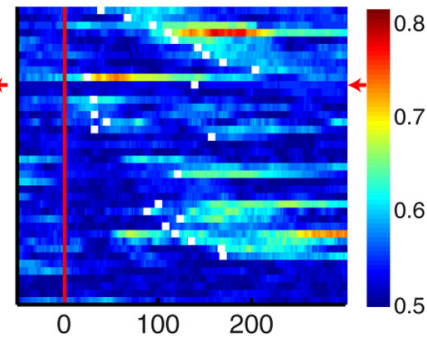

Time from cue onset (ms)

$I_{A P}=$ Index attention - Index position

(3) $I_{A P}$ over time
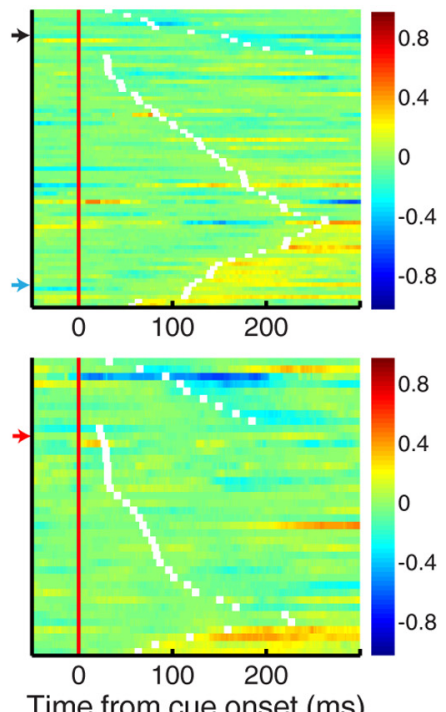

Time from cue onset (ms)
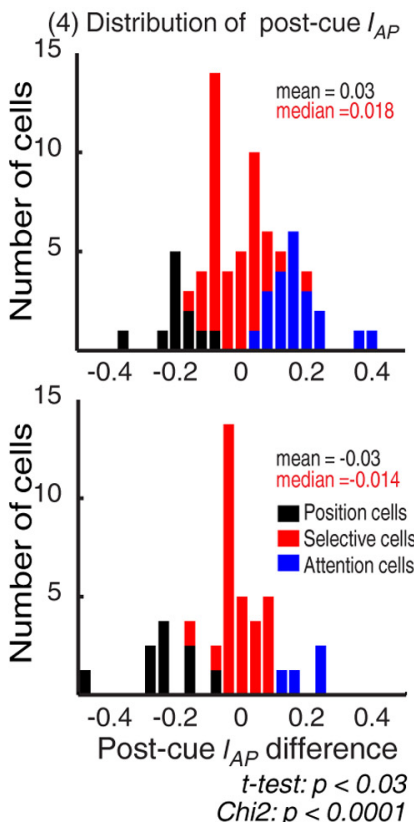

Figure 4. Cue-related activities: population responses. 1, ROC values in time comparing neuronal responses with contralateral versus ipsilateral attention orientation instruction for both FEF cells (top, each line corresponds to a cell) and LIP cells (bottom). 2, ROC values in time comparing neuronal responses with contralateral versus ipsilateral cues. 3, Comparison for each cell of the strength with which they discriminate the final position of attention compared with cue position over time. $I_{\mathrm{AP}}$ index is the average difference between two instantaneous attention and position indexes, computed using a randomized bootstrap method ( $n=10,000$, see Materials and Methods for details). White ticks correspond to cue-response latency for each cell. In $\mathbf{1}, \mathbf{2}$, and $\mathbf{3}$, ROC significance $(\mathbf{1 , 2})$ or earliest cue-response $(\mathbf{3})$ onset is signified for each cell by a white dot. 4, Distribution of average $I_{\mathrm{AP}}$ over a window of $50 \mathrm{~ms}$ after cue-response onset is also represented for both FEF and LIP cell populations. Three cell categories are defined: position cue cells in black, selective cue cells in red, and attention cue cells in blue. Cells in 1, 2, and $\mathbf{3}$ are ordered a posteriori along the $y$-axis to cluster into these three cell categories from high to low response latencies for categories "position" and "attention" and low to high response latencies for category "cue-selective" (color coded as in 4 along the $y$-axis of the left panel).

window after cue-related response onset (see "Cue classification" section in Materials and Methods for details). In this time window, the attention index of position cue cells was on average significantly lower than their position index (Fig. 4-4, black distribution). The attention index of attention cue cells was on average significantly higher than their position index (Fig. 4-4, blue distribution). The remaining cells, defining the selective cue cells, had an attention index that was not significantly different from their position index (Fig. 4-4, red distribution). As predicted by this categorization, the position cue cell population of both FEF and LIP specifically encoded cue position, whereas the attention cue cells population of both areas specifically encoded the attention instruction held by the cue (Fig. 5). As could already be suspected from the two distributions shown in Figure 4-4, the overall representation of these functional cue-related cell subtypes were significantly different between the two areas $\left(\chi^{2}\right.$, $\mathrm{df}=2, p<0.0001)$. This difference cannot be explained by the cue-selective cells, which are represented in large proportions in both areas (FEF: $n=40 / 72,55 \%$; LIP: $n=27 / 40,67 \%$ ), nor by the position cells (FEF: $n=11 / 72,15 \%$; LIP: $n=9 / 40,22 \%$ ), but by the higher proportion of attention cells in FEF than in LIP (FEF: $n=21 / 72,29 \%$; LIP: $n=4 / 40,10 \%$ ). This suggests a differential contribution of FEF and LIP to cue analysis. Although both LIP and FEF are involved in the analysis of the intrinsic properties of the cue such as its position or its color, FEF appears to dedicate more resources to the analysis of the extrinsic properties of the cue and the mapping of the attentional cue instruction onto space than LIP.

This latter operation requires integrating both the identity and the position of the cue. Encoding attention can thus be predicted to take longer than encoding cue position or cue identity.
To test this hypothesis, we compared the cue-response latencies of the different cell categories across both areas. The first major observation of this analysis was that cue-related responses had an overall earlier onset in LIP than in the FEF (Fig. 6, left, median = 83 vs $136 \mathrm{~ms}$, Wilcoxon rank test, $p<0.001$ ). Comparing response latencies as a function of the above-described cell categories brings about a second major observation. The response of LIP selective cue-related cell class (median $=70 \mathrm{~ms}$ ) precedes all other cell categories (Wilcoxon rank test, $p<0.05$ or lower). In particular, it has a shorter latency than position cue-related LIP cells (median $=117$ ms, Fig. 6, middle, Wilcoxon rank test, $p<$ $0.05)$. This result suggests that the signal arising from this later population is a processing step away from the selective cuerelated cell class and might play an active role in the computations that LIP is performing during this specific period of the task. The latency of FEF selective cue-related cells (median $=123 \mathrm{~ms}$ ) and position cue-related cells (median $=121 \mathrm{~ms}$, Fig. 6) are not significantly different from each other (Wilcoxon rank test, $p=$ 0.77 ), whereas the latency of FEF-selective cue-related cells is significantly different from that of LIP selective cue-related cells $(p<0.007)$. Of major interest is the observation that FEF attention cue-related cells lag all other cell categories (median $=150$ $\mathrm{ms}$, significant or close to significant comparison with all cue-cell subtypes except FEF cue position cells: Wilcoxon rank test comparison with FEF cue selective cells, $p=0.01$; Wilcoxon rank test comparison with LIP cue position cells, $p=0.06$ ). Note that LIP attention cells are not included in the present analysis due to their small number (four cells). These temporal relationships and their statistical significance remained unchanged when ROCs were performed over 60 or $40 \mathrm{~ms}$ averaging windows and when cuerelated cell response latencies were estimated using a sliding 


\section{FEF population response to cue}
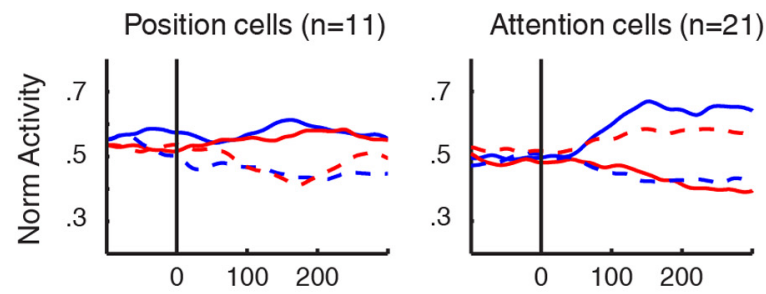

Responses to individual cues

- Stay contra

_ _ . Stay ipsi

_ Shift from contra to ipsi

- _ . Shift from ipsi to contra
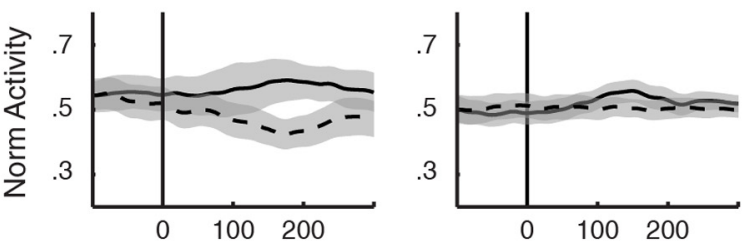

Responses to cue position

- Cue contra

- . . Cue ipsi

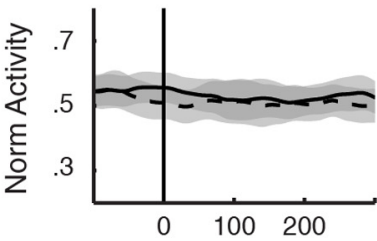

Time from cue onset (ms)

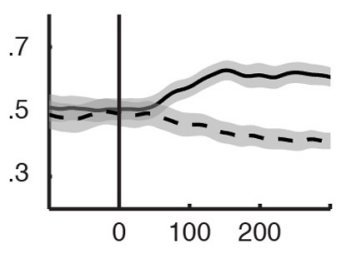

Time from cue onset (ms)
Responses to final attention position

- Att contra

- _ Att ipsi

\section{LIP population response to cue}
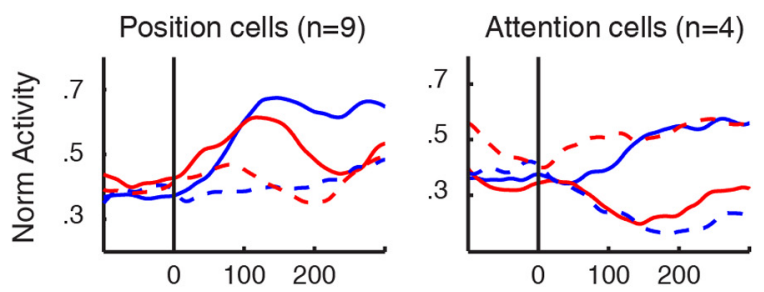

Responses to individual cues

_ Stay contra

- _ . Stay ipsi

_ Shift from contra to ipsi - _ . Shift from ipsi to contra
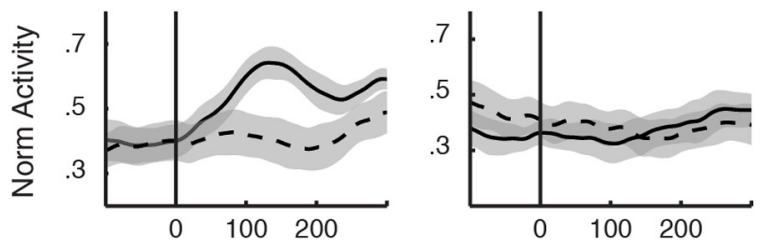

Responses to cue position

- Cue contra

_ - . Cue ipsi

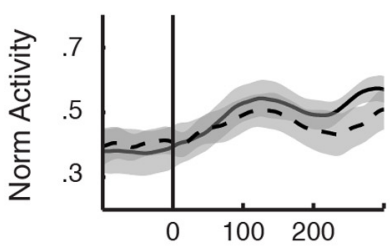

Time from cue onset (ms)

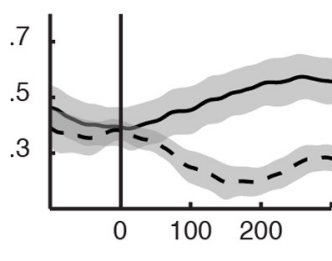

Responses to final attention position

- Att contra

- . Att ipsi

The cue-selective cells that we identified can individually encode neither the position of the cue nor the final instructed position of attention (in contrast to the position and attention cue cells). However, a minimal population composed of a Stay contralateral, a Stay ipsilateral, a Shift contralateral, and a Shift ipsilateral selective cue cell (four cells in all) holds all of the necessary information to encode either the position of the cue or the final position of attention. The average onset latency of an attention or position ROC significance can be considered as an approximation of the time at which a potential coding of attention or position emerges from the LIP and FEF cueselective cell populations. On average, the attention ROC curves reach significance $116 \pm 69 \mathrm{~ms}$ in LIP and $134 \pm 58 \mathrm{~ms}$ in FEF (no statistical difference between these two latency distributions, Wilcoxon test, $p>0.1)$. In comparison, the position ROC curves reached significance $100 \pm$ $54 \mathrm{~ms}$ in LIP and $114 \pm 81 \mathrm{~ms}$ in FEF (no statistical difference between these two latency distributions, Wilcoxon test, $p>$ 0.2 ). As a result, if these selective cell populations do indeed contribute to attention and position, then they most probably do so with the same timing (see Discussion).

Interestingly, the emergence of an explicit attention selectivity in the FEF at 150 $\mathrm{ms}$ is consistent with the animal's behavior. Indeed, although human subjects achieve maximum DRs for targets presented $400 \mathrm{~ms}$ after cue onset (Ibos et al., 2009, Fig. 3), the DRs of both monkeys were already at their maximum as early as $150 \mathrm{~ms}$ after cue onset (Table 2; Monkey M: one-way ANOVA on DR with CTOA as main factor, $p<0.001$, a TukeyCramer post hoc test indicates that DR at CTOAs 150 and 300 cannot be distinguished one from the other, and are significantly higher than DR at CTOAs 600 and 900, $p<0.01$; Monkey Z: one-way ANOVA on DR with CTOA as main factor, $p<0.001$, a Tukey-Cramer post hoc test indicates that DR at CTOAs 150, 300, and 600 cannot be distinguished one from the other and are significantly higher than DR at CTOA 900, $p<0.05)$.

\section{Target-related responses}

Both LIP (Gottlieb et al., 1998; Kusunoki ANOVA procedure. The overall emerging temporal sequence is the following: LIP-selective cue cells respond first, followed by LIP position cue cells, FEF-selective cue cells, and FEF position cue cells that cluster at intermediate latencies. FEF attention cue cells respond last, suggesting that they might be the product of local computations combining cue position and cue identity to extract the final instructed position of attention. et al., 2000; Toth and Assad, 2002) and FEF (Bichot et al., 1996) are selective to the key stimuli of a behavioral task. Here, we compared how the detected target is represented in both areas. FEF neurons showed robust target-related responses in equivalent proportions $(85 / 99,86 \%)$ to LIP $(52 / 63,82 \%)$. This was expected given that the target is the single most behaviorally significant stimulus of the task. In the following, we will specifically 
Table 2. DRs as a function of CTOA for monkeys $M$ and $Z$

\begin{tabular}{lcccr}
\hline & CTOA & & & \\
\cline { 2 - 5 } & $150 \mathrm{~ms}$ & $300 \mathrm{~ms}$ & $600 \mathrm{~ms}$ & $900 \mathrm{~ms}$ \\
\hline DR (mean \pm SD) & & & & \\
$\quad$ Monkey M & $85 / 21$ & $86.2 / 15.4$ & $77.4 / 19.7$ & $64.4 / 24.7$ \\
Monkey Z & $73.7 / 21.7$ & $78.9 / 18.9$ & $73.9 / 18.8$ & $64 / 17.6$ \\
\hline DRs are cumulated over shift and stay trials because there is no cue type main factor effect (one-way ANOVA, monkey \\
M, $p>0.35$; monkey Z, $p>0.1$ ).
\end{tabular}

focus on cells with spatially selective phasic responses to the detected target (FEF, 66/85, 78\%; LIP, 40/52, 77\%). Figure 3-4 shows the response of a representative FEF neuron to a target presented inside its RF (black) or in the opposite hemifield (gray) on valid trials. After cue presentation, this cell encodes the instructed attentional orientation in a sustained manner up to target presentation. When the target is presented, a specific target-related response builds up on this anticipatory component. Figure 3-1 shows the response of a representative LIP target-related neuron to a target predicted and presented contralaterally (black) or ipsilaterally (gray) to its RF. This cell specifically encodes the presence of the target in its receptive field, but does not show the FEF neuron's anticipatory response. However, at the population level for both FEF and LIP, activity before the presentation of a contralateral target was significantly higher than before an ipsilateral target (Fig. 7-1,2). This activity can be interpreted as an attentional spatial signal resulting from the interpretation of the advanced information provided by the cue about target position. The presence of such a signal is not surprising in the FEF given the high proportion of attention cue cells that specifically represent this advanced information and the high overlap between these unilateral target-related neurons with cuerelated neurons $(49 / 66,74 \%)$. An attentional signal as observed here in LIP has also been described previously (Herrington et al., 2009). It is unlikely that the $10 \%(n=4)$ LIP attention cuerelated cells are on their own driving this population anticipatory response. This signal could thus correspond to the output of local computations combining cue position signals and cue identity signals (cue and target LIP cell overlap, 22/40, 55\%) or it could reflect top-down endogenous influences from the FEF onto LIP, as suggested previously (Ekstrom et al., 2008).

In view of the striking similarities between LIP and FEF in the allocation of neuronal resources to target processing, the question arises as to whether this processing takes place in parallel or according to a temporal hierarchy between the two areas. Population response curves to contralateral targets (Fig. 7-1,2) suggest that FEF is responding to target presentation earlier than LIP. To better characterize this observation, response latencies were thus calculated for each cell (see "Latency of target-related cells" section in Materials and Methods). We found that FEF had a significantly shorter median target response latency (166 ms) than LIP (206 ms, Wilcoxon rank test, $p=0.0339$, Fig. 8). This temporal relationship between the neuronal responses of both areas is the opposite of the cue-related responses latencies described above.

\section{Discussion}

The present experiment relied on the analysis of the neuronal responses to the two key events of a cued target detection task, namely the cue and the target, which allows the distinction between two cognitive processes in time, the voluntary orientation of spatial attention, and target detection. Our results clearly support a functional dissociation between areas LIP and FEF in relation to these processes.
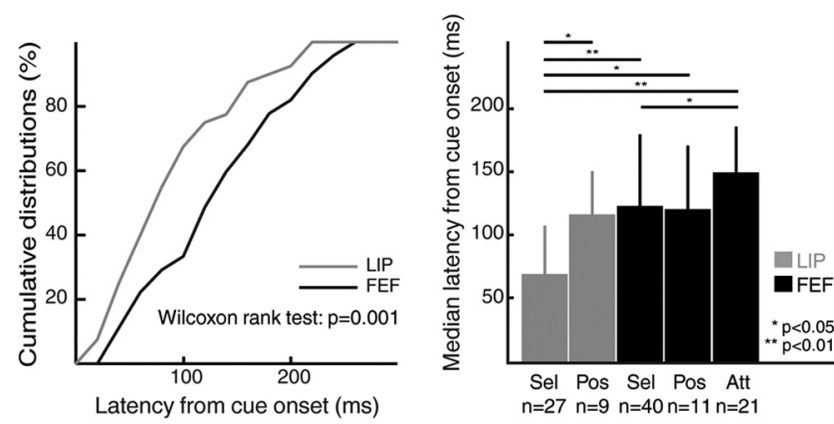

Figure 6. Cue-related activities: cell latency analysis. Left: Cumulative distribution of cueresponse latencies for both FEF (black) and LIP (gray). Right: Median latency (plus median absolute deviation) for each cue subpopulation. Sel indicates selective cue cells; Pos, position cue cells; Att, attention cue cells. No values were available for the LIP Att category because $n=$ 4. ${ }^{*} p<0.05 ;{ }^{* *} p<0.01$, Wilcoxon rank test.

\section{Neuronal substrates for endogenous attention control predominate within the prefrontal cortex compared with the parietal cortex}

We show that over $25 \%$ of FEF cue-related cells specifically and explicitly encode the spatial instruction of the cue independently of its position or its identity. These cells thus reflect the spatial allocation of attention that results from the interpretation of the cue. This observation is consistent with prior electrophysiological studies demonstrating neuronal correlates of attentional spatial selection in the FEF (Thompson et al., 2005; Armstrong et al., 2009; Zhou and Thompson, 2009). The average response latency of this cell population is $40 \mathrm{~ms}$ longer than that of the remaining cue-related cells, suggesting that the attentional signal that they carry arises from local computations and is extracted from the cue position and the cue identity information available within the FEF. This view is consistent with the previous studies showing that the spatial attention signal emerges in the FEF spikes before it does on local field potential (Monosov et al., 2008) and the central role attributed to the FEF in the top-down control of attention (Ekstrom et al., 2008; Gregoriou et al., 2009; Noudoost et al., 2010; Noudoost and Moore, 2011).

We also show that only $10 \%$ of the LIP cue-related cells carry an explicit coding of attention orientation. The weakness of this signal in the parietal cortex compared with the prefrontal cortex calls for a reevaluation of its exact role in attention control. Indeed, although there is ample evidence for the contribution of LIP to exogenous attentional processes (Ipata et al., 2006; Arcizet et al., 2011) and in the integration of exogenous (stimulusdriven) and endogenous (goal-directed) salience factors (Gottlieb et al., 1998; Bisley and Goldberg, 2003), the present data suggest that it is not at the source of endogenous attentional control.

The exact role of the cue-selective neurons is unclear. One possibility is that this population provides an implicit distributed encoding of both cue position and instructed attention. In the FEF, these cells could serve as computational intermediates to the final coding of instructed attention by the attention cells. In the LIP, given the scarcity of attention cells, attention would be coded only in a distributed manner and not maintained over time (Fig. 4-1). Although it is unclear why LIP and FEF would be encoding attention differently, this possibility needs to be considered. Alternatively, this population of cue-selective cells could represent a functional selectivity to the color of the cue, a feature that is fundamental to the interpretation of the cues (Toth and Assad, 2002). A last possibility is that this population encodes 
1. FEF target-related normalized population response

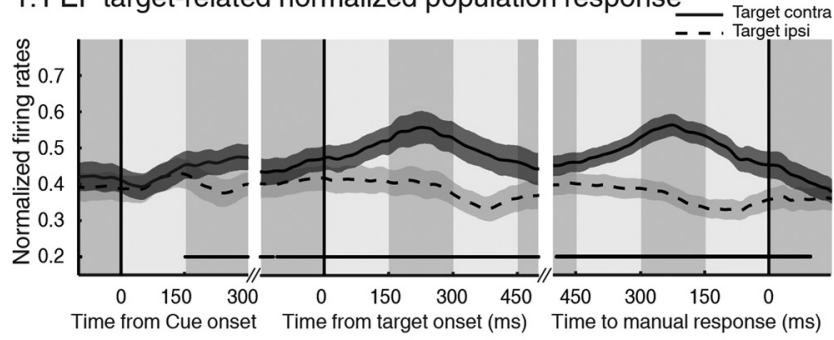

2. LIP target-related normalized population response

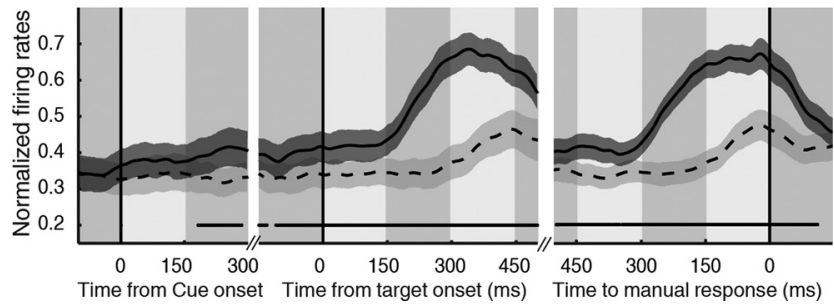

Figure 7. Target-related activities: population responses. FEF (1) and LIP (2) target-related normalized population activities to a target expected and predicted contralaterally (black) or ipsilaterally (gray), successively aligned on cue, target, and manual response onsets (mean \pm SE). Statistically significant differences between the two conditions are represented by the horizontal black line (paired $t$ test, $p<0.05$ ).

partial information about task rules as described by Stoet and Snyder (2004). Further experiments involving a direct manipulation of task rules and cue color would be required to reach a conclusion about the role of this population.

\section{Spatial attention response biases within the \\ frontoparietal cortex}

Despite the fact that individual neurons encoding the attentional interpretation of the cue are scarce in LIP, its population activity shows a spatially selective bias toward the predicted target location; this bias is very similar to the one observed before the target in the FEF. In both areas, this attentional signal most probably contributes to the facilitation of target detection, allowing a quicker rise of neuronal activity to a decision threshold (Herrington and Assad, 2009).

Both on the basis of the present work and the known high connectivity between LIP and the FEF (Cavada and GoldmanRakic, 1989; Stanton et al., 1995), we suggest that this enhanced pretarget LIP activity is the expression of a top-down modulation arising in the FEF. The experimental design used here allows us to obviate the confound between attention orientation and detection processes. We propose that the enhancement of LIP's visual responses to behaviorally relevant stimuli, which has classically been considered to be the hallmark of endogenous attention in such tasks as peripheral attention, memory guided saccades, or visual search (Colby et al., 1996; Gottlieb et al., 2005; Ipata et al., 2006; Herrington and Assad, 2009), is thus best described as resulting from the top-down facilitatory influences originating in the FEF.

\section{Information flow within the parietofrontal network}

Our data reveal a dual information flow within the parietofrontal network (Fig. 9). Despite the fact that cue-induced attention orientation signals originate within the prefrontal cortex, the cue appears to be processed in the parietal cortex an average of $40 \mathrm{~ms}$ before being processed in the prefrontal cortex. Conversely, although both LIP and FEF are found to convey enhanced target-

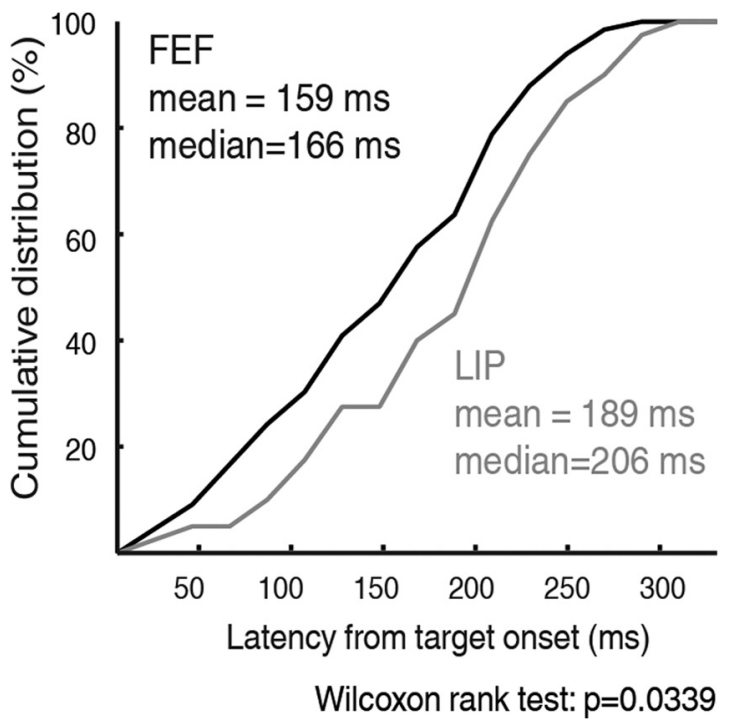

Figure 8. Cumulative latency distributions of target-related neurons in areas FEF (black) and LIP (gray).

related signals suitable to contribute to target processing and its perceptual report, FEF target-related cells respond, on average, $40 \mathrm{~ms}$ before LIP target-related cells. What in the nature of the cue, the target, and our task could account for these differential parietofrontal information flows?

Both the cue and the target events need to be selected among the distractors and interpreted by the monkey to perform the task successfully. As a result, both have an extrinsic saliency that is expected to be processed in a top-down manner. Both of them also have an intrinsic saliency (color for the cue and spatial frequency for the target) that contrasts with the visual properties of the distractors. However, the task was designed such that the monkey could readily identify the cue event among the distractors - the processing pressure being on its proper interpretation. In contrast, the saliency of the target was decreased so that the monkeys benefited from advanced cue information and maintained an average performance $<80 \%$. As a result, the cuedistractor contrast was higher than the target-distractor contrast. This differential intrinsic salience could account for the differential temporal information flow that we report between the parietal and prefrontal cortex in processing the cue and the target. Specifically, the relatively high cue to distractor contrast could account for the earlier involvement of LIP in its processing than the FEF, thus describing a bottom-up information flow within the parietofrontal network as suggested previously (Buschman and Miller, 2007). In contrast, the low target-to-distractor contrast would account for the prefrontal temporal advantage over the parietal cortex, thus describing a top-down information flow within this functional network (Buschman and Miller, 2007). Earlier in this discussion, we described evidence supporting the idea that FEF is at the source of voluntary attention orientation signals and this, together with the prefrontal cortex priority in processing the low-contrast target, suggests that the FEF plays a key role in the processing of endogenous information compared with LIP.

We have further refined the temporal hierarchy of cue processing between the parietal and prefrontal cortex. LIP cells encode a specific type of cue at a specific location, on average, $40 \mathrm{~ms}$ before other LIP or FEF cue-related cells. This is a confirmation of the highly dynamic task-dependent visual representation held by 


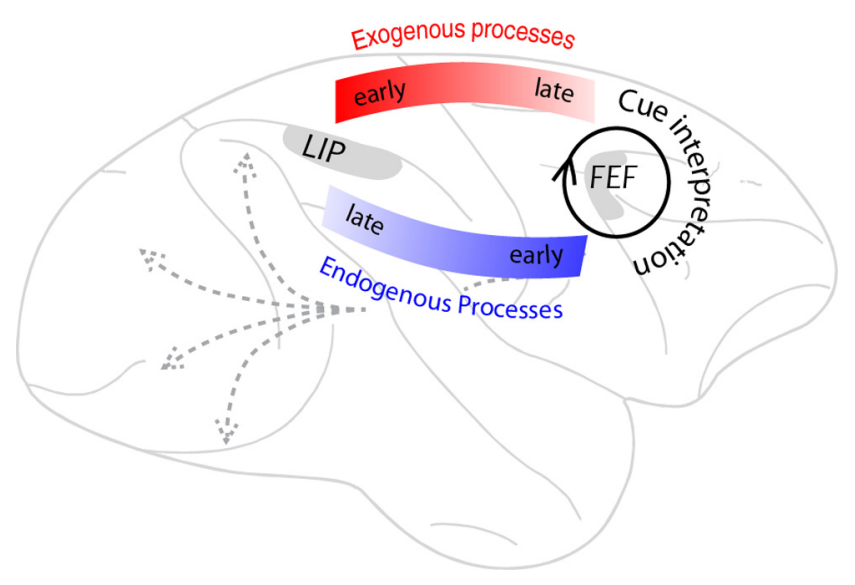

Figure 9. Functional hierarchy within the parietofrontal network in stimulus selection and attention control. The exogenous processing of the cue (red) starts on average earlier in LIP than in FEF. Cue interpretation takes place most prominently in the FEF. The resulting spatial selection and the endogenous processing of the target (blue) starts on average earlier in the FEF than in LIP. This top-down signal presumably modulates the extrastriate and the striate cortex (dashed gray arrows). This description is compatible with other functions assigned to the parietofrontal network (see Discussion).

LIP (Sereno and Maunsell, 1998; Ben Hamed et al., 2002; Toth and Assad, 2002; Freedman and Assad, 2006; Fanini and Assad, 2009; Fitzgerald et al., 2011). The very short response latencies of this LIP cell category compared with the FEF equivalent category match a recent study comparing parietal and prefrontal cortex categorization responses (Swaminathan and Freedman, 2012). These very short latencies could correlate with the fact that the monkeys have progressively become experts in the required task. If this is indeed the case, we predict that these cue-selective cells arise progressively in LIP, whereas their latencies become shorter as learning progresses. Interestingly, our observations indicate that the encoding of cue position follows in time the encoding of cue selectivity described above. Our report of the average latency at which cue position is signaled is very similar to that described in a recent study investigating bottom-up spatial selection between the parietal and the dorsolateral prefrontal cortex (Katsuki and Constantinidis, 2012). The exact relationship between the cue-selective and cue position responses, if any, remains to be investigated.

\section{References}

Arcizet F, Mirpour K, Bisley JW (2011) A pure salience response in posterior parietal cortex. Cereb Cortex 21:2498-2506. CrossRef Medline

Armstrong KM, Chang MH, Moore T (2009) Selection and maintenance of spatial information by frontal eye field neurons. J Neurosci 29: 15621-15629. CrossRef Medline

Ben Hamed S, Duhamel JR (2002) Ocular fixation and visual activity in the monkey lateral intraparietal area. Exp Brain Res 142:512-528. CrossRef Medline

Ben Hamed S, Duhamel JR, Bremmer F, Graf W (2002) Visual receptive field modulation in the lateral intraparietal area during attentive fixation and free gaze. Cereb Cortex 12:234-245. CrossRef Medline

Bichot NP, Schall JD, Thompson KG (1996) Visual feature selectivity in frontal eye fields induced by experience in mature macaques. Nature 381:697-699. CrossRef Medline

Bisley JW, Goldberg ME (2003) Neuronal activity in the lateral intraparietal area and spatial attention. Science 299:81-86. CrossRef Medline

Bruce CJ, Goldberg ME, Bushnell MC, Stanton GB (1985) Primate frontal eye fields. II. Physiological and anatomical correlates of electrically evoked eye movements. J Neurophysiol 54:714-734. Medline

Buschman TJ, Miller EK (2007) Top-down versus bottom-up control of attention in the prefrontal and posterior parietal cortices. Science 315: 1860-1862. CrossRef Medline
Cavada C, Goldman-Rakic PS (1989) Posterior parietal cortex in rhesus monkey: II. Evidence for segregated corticocortical networks linking sensory and limbic areas with the frontal lobe. J Comp Neurol 287:422-445. CrossRef Medline

Chafee MV, Goldman-Rakic PS (2000) Inactivation of parietal and prefrontal cortex reveals interdependence of neural activity during memoryguided saccades. J Neurophysiol 83:1550-1566. Medline

Colby CL, Goldberg ME (1999) Space and attention in parietal cortex. Annu Rev Neurosci 22:319-349. CrossRef Medline

Colby CL, Duhamel JR, Goldberg ME (1996) Visual, presaccadic, and cognitive activation of single neurons in monkey lateral intraparietal area. J Neurophysiol 76:2841-2852. Medline

Corbetta M, Shulman GL (2002) Control of goal-directed and stimulusdriven attention in the brain. Nat Rev Neurosci 3:201-215. CrossRef Medline

Ekstrom LB, Roelfsema PR, Arsenault JT, Bonmassar G, Vanduffel W (2008) Bottom-up dependent gating of frontal signals in early visual cortex. Science 321:414-417. CrossRef Medline

Fanini A, Assad JA (2009) Direction selectivity of neurons in the macaque lateral intraparietal area. J Neurophysiol 101:289-305. CrossRef Medline

Fitzgerald JK, Freedman DJ, Assad JA (2011) Generalized associative representations in parietal cortex. Nat Neurosci 14:1075-1079. CrossRef Medline

Freedman DJ, Assad JA (2006) Experience-dependent representation of visual categories in parietal cortex. Nature 443:85-88. CrossRef Medline

Gnadt JW, Andersen RA (1988) Memory related motor planning activity in posterior parietal cortex of macaque. Exp Brain Res 70:216-220. Medline

Gottlieb JP, Kusunoki M, Goldberg ME (1998) The representation of visual salience in monkey parietal cortex. Nature 391:481-484. CrossRef Medline

Gottlieb J, Kusunoki M, Goldberg ME (2005) Simultaneous representation of saccade targets and visual onsets in monkey lateral intraparietal area. Cereb Cortex 15:1198-1206. CrossRef Medline

Green CG, Swets JA, eds (1966) Signal detection theory and psychophysics. New York: Wiley.

Gregoriou GG, Gotts SJ, Zhou H, Desimone R (2009) High-frequency, long-range coupling between prefrontal and visual cortex during attention. Science 324:1207-1210. CrossRef Medline

Hays AV, Richmond BJ, Optican LM (1982) A UNIX-based multipleprocess system for real-time acquisition and control. WESCON Conf Proc 2:1-10.

Herrington TM, Assad JA (2009) Neural activity in the middle temporal area and lateral intraparietal area during endogenously cued shifts of attention. J Neurosci 29:14160-14176. CrossRef Medline

Herrington TM, Masse NY, Hachmeh KJ, Smith JE, Assad JA, Cook EP (2009) The effect of microsaccades on the correlation between neural activity and behavior in middle temporal, ventral intraparietal, and lateral intraparietal areas. J Neurosci 29:5793-5805. CrossRef Medline

Ibos G, Duhamel JR, Ben Hamed S (2009) The spatial and temporal deployment of voluntary attention across the visual field. PLoS One 4:e6716. CrossRef Medline

Ipata AE, Gee AL, Gottlieb J, Bisley JW, Goldberg ME (2006) LIP responses to a popout stimulus are reduced if it is overtly ignored. Nat Neurosci 9:1071-1076. CrossRef Medline

Katsuki F, Constantinidis C (2012) Early involvement of prefrontal cortex in visual bottom-up attention. Nat Neurosci 15:1160-1166. CrossRef Medline

Kusunoki M, Gottlieb J, Goldberg ME (2000) The lateral intraparietal area as a salience map: the representation of abrupt onset, stimulus motion, and task relevance. Vision Res 40:1459-1468. CrossRef Medline

Lamme VA (2004) Separate neural definitions of visual consciousness and visual attention; a case for phenomenal awareness. Neural Netw 17:861872. CrossRef Medline

Monosov IE, Thompson KG (2009) Frontal eye field activity enhances object identification during covert visual search. J Neurophysiol 102: 3656-3672. CrossRef Medline

Monosov IE, Trageser JC, Thompson KG (2008) Measurements of simultaneously recorded spiking activity and local field potentials suggest that spatial selection emerges in the frontal eye field. Neuron 57:614-625. CrossRef Medline

Moore T, Armstrong KM (2003) Selective gating of visual signals by microstimulation of frontal cortex. Nature 421:370-373. CrossRef Medline 
Moore T, Fallah M (2004) Microstimulation of the frontal eye field and its effects on covert spatial attention. J Neurophysiol 91:152-162. CrossRef Medline

Noudoost B, Moore T (2011) Control of visual cortical signals by prefrontal dopamine. Nature 474:372-375. CrossRef Medline

Noudoost B, Chang MH, Steinmetz NA, Moore T (2010) Top-down control of visual attention. Curr Opin Neurobiol 20:183-190. CrossRef Medline

Premereur E, Vanduffel W, Janssen P (2011) Functional heterogeneity of macaque lateral intraparietal neurons. J Neurosci 31:12307-12317. CrossRef Medline

Sereno AB, Maunsell JH (1998) Shape selectivity in primate lateral intraparietal cortex. Nature 395:500-503. CrossRef Medline

Stanton GB, Bruce CJ, Goldberg ME (1995) Topography of projections to posterior cortical areas from the macaque frontal eye fields. J Comp Neurol 353:291-305. CrossRef Medline

Stoet G, Snyder LH (2004) Single neurons in posterior parietal cortex of monkeys encode cognitive set. Neuron 42:1003-1012. CrossRef Medline

Swaminathan SK, Freedman DJ (2012) Preferential encoding of visual categories in parietal cortex compared with prefrontal cortex. Nat Neurosci 15:315-320. CrossRef Medline

Theeuwes J (1993) Visual selective attention: a theoretical analysis. Acta Psychol (Amst) 83:93-154. CrossRef Medline

Thompson KG, Bichot NP (2005) A visual salience map in the primate frontal eye field. Prog Brain Res 147:251-262. CrossRef Medline
Thompson KG, Biscoe KL, Sato TR (2005) Neuronal basis of covert spatial attention in the frontal eye field. J Neurosci 25:9479-9487. CrossRef Medline

Toth LJ, Assad JA (2002) Dynamic coding of behaviourally relevant stimuli in parietal cortex. Nature 415:165-168. CrossRef Medline

Wardak C, Olivier E, Duhamel JR (2004) A deficit in covert attention after parietal cortex inactivation in the monkey. Neuron 42:501-508. CrossRef Medline

Wardak C, Ibos G, Duhamel JR, Olivier E (2006) Contribution of the monkey frontal eye field to covert visual attention. J Neurosci 26:4228 -4235. CrossRef Medline

Yantis S, Schwarzbach J, Serences JT, Carlson RL, Steinmetz MA, Pekar JJ, Courtney SM (2002) Transient neural activity in human parietal cortex during spatial attention shifts. Nat Neurosci 5:995-1002. CrossRef Medline

Zénon A, Ben Hamed S, Duhamel JR, Olivier E (2009a) Attentional guidance relies on a winner-take-all mechanism. Vision Res 49:1522-1531. CrossRef Medline

Zénon A, Ben Hamed S, Duhamel JR, Olivier E (2009b) Visual search without attentional displacement. J Vis. 9:9 1-15. Medline

Zhou HH, Thompson KG (2009) Cognitively directed spatial selection in the frontal eye field in anticipation of visual stimuli to be discriminated. Vision Res 49:1205-1215. CrossRef Medline 